\title{
Laparoscopically assisted gastric resections: a word of caution
}

\author{
Mike T. Hallissey \\ Department of Surgery, Queen Elizabeth Hospital, Ward West 2, Edgbaston, Birmingham B15 2TH, UK
}

The advent of new surgical techniques is to be welcomed. Our hopes of improving the care of our patients is the driving force behind the many innovations that have occurred in surgery over the last 50 years. However, we now work in a profession that strives to provide evidence-based care, and the surgical community has an obligation to see these techniques introduced in a controlled and appropriate manner.

When laparosopic surgery was introduced in the late 1980s, the introduction was uncontrolled and the price for this was an increase in the rate of avoidable complications. The lessons of the introduction of the early laparoscopic procedures, particularly laparoscopic cholecystectomy, must be used to provide a safe environment for the introduction of other forms of novel laparoscopic surgery.

In surgical oncology there are two aspects to the practice that require evaluation before these techniques should be advocated for widespread use. Uyama's paper in this issue of the journal [1] describes a technical solution to the delivery of part of a laparoscopic resection for cancer and demonstrates that the procedure is feasible. This paper, with a number of others, has demonstrated that the procedure is deliverable, but the publications to date are largely case studies or retrospective analyses [2-5]. However, not all deliverable procedures result in an improvement in the overall care of the patient. It is vital with the evolution of laparoscopic or laparoscopically assisted surgery for gastric cancer that it is subject to the same rigorous standards of evaluation as the introduction of other forms of novel therapies.

There was immense interest and enthusiasm for the introduction of laparoscopic colorectal surgery, and this has now been tempered by experience. The value of the technique is now subject to a number of randomized trials, and evaluation of the data by the National Insti-

Offprint requests to: M.T. Hallissey

Received: June 25, 2001 / Accepted: June 26, 2001 tute for Clinical Excellence in the UK has recommended that the technique is undertaken only as a part of a clinical trial. It is vital that the pioneers of laparoscopic gastric cancer surgery adopt a similar approach in disseminating their learning and then involving themselves in the rigorous evaluation of the technique in large randomized trials. The advantages of laparoscopic surgery are short term, with reduced postoperative discomfort and length of stay being the major factors. However, it is vital to ensure that these shortterm gains do not result in long-term losses with increases in the rate of local or distant recurrence or impaired survival.

The surgical community has been the subject of much criticism from the medical press for our failure to undertake randomized trials of our treatments [6]. It behoves us all to take this to heart and ensure that we work to the highest standards in the evolution of the art and the science of surgery.

\section{References}

1. Uyama I, Sugioka A, Matsui H, Fujita J, Komori Y, Hatakawa Y, Hasumi A. Laparoscopic side-to-side esophagogastrostomy using a linear stapler after proximal gastrectomy. Gastric Cancer 2001;4: 98-102.

2. Adachi Y, Suematsu T, Shiraishi N, Katsuta T, Morimoto A, Kitano S, et al. Quality of life after laparoscopy-assisted Billroth I gastrectomy. Ann Surg 1999;229:49-54.

3. Adachi Y, Shiraishi N, Shiromizu A, Bandoh T, Aramaki M, Kitano S. Laparoscopy-assisted Billroth I gastrectomy compared with conventional open gastrectomy. Arch Surg 2000;135:80610.

4. Shimizu S, Uchiyama A, Mizumoto K, Morisaki T, Nakamura K, Shimura $\mathrm{H}$, et al. Laparoscopically assisted distal gastrectomy for early gastric cancer: is it superior to open surgery? Surg Endosc 2000;14:27-31.

5. Shiraishi N, Adachi Y, Kitano S, Bandoh T, Katsuta T, Morimoto A. Indication for and outcome of laparoscopy-assisted Billroth I gastrectomy. Br J Surg 1999;86:541-4.

6. Horton R. Surgical research or comic opera: questions but few answers. Lancet 1996;347:984-5. 